\title{
Obstructive sleep apnea and non-sustained ventricular tachycardia in patients with advanced chronic kidney disease and mild left ventricular dysfunction
}

\author{
Márcio Galindo Kiuchi ${ }^{1 *}$ and Shaojie Chen ${ }^{2}$ \\ ${ }^{1}$ Cardiac Surgery and Artificial Cardiac Stimulation Division, Department of Medicine, Hospital e Clínica São Gonçalo, São Gonçalo, RJ, Brazil \\ ${ }^{2}$ Department of Cardiology, Shanghai First People's Hospital, Shanghai Jiao Tong University School of Medicine, Shanghai, China
}

\begin{abstract}
Purpose: We conjectured that obstructive sleep apnea (OSA) is associated with an increased risk of ventricular arrhythmias freely of other risk issues and that the harshness of OSA is directly allied with the extent of this risk. In this curent study, we assessed the effects of clonazepam and zolpidem in OSA in patients with advanced chronic kidney disease (CKD) and mild left ventricular (LV) dysfunction.

Methods: This transversal study involved 30 patients with CKD stage 4, fifteen of them using clonazepam 2 mg and the other 15 patients using zolpidem $10 \mathrm{mg}$ before to sleep due to a disturbance to sleep.

Results: During the polysomnography, the group using clonazepam $2 \mathrm{mg}$ showed a higher apnea/hypopnea index events (47.3 \pm 6.5 events/hour) in comparison with the group using zolpidem $10 \mathrm{mg}(10.4 \pm 3.3$ events/hour), $\mathrm{P}<0.0001$. The 24-hour Holter monitoring presented a mean number of non-sustained ventricular tachycardia (NSVT) during the day, night, and whole period, respectively of $3.1 \pm 1.9,18.2 \pm 2.1$, and $10.7 \pm 2.0$ for the subjects using 2 mg of clonazepam, as well as, $9.4 \pm 2.5,3.3 \pm 1.5$, and $6.3 \pm 1.8$ for the individuals using zolpidem $10 \mathrm{mg}$ (all the comparisons between groups into the same period were significant, $\mathrm{P}<0.0001$ for all of them)
\end{abstract}

Conclusion: There were the highest number of AHI events in patients using clonazepam $2 \mathrm{mg}$ than in those using zolpidem $10 \mathrm{mg}$, as well as, a major incidence of NSVT in the first group compared to the second one, during the whole period recorded by the 24-hour Holter monitoring.

\section{Introduction}

Sleep complications are frequently seen in subjects with chronic kidney disease (CKD). These difficulties vary in nature and assortment from insomnia to obstructive sleep apnea (OSA). Insomnia has been described in nearly $60 \%$ of individuals on hemodialysis (HD), stretching from the struggle in falling asleep in approximately half of the patients to difficulty in sleep keep in a quarter of subjects [1]. This is further than estimated population prevalence of around $15 \%$. Sleep illnesses are not just comorbid with CKD reasonably they may be pathophysiologically connected to this disease. Psychological, as well as biological aspects, impact the sleep among CKD subjects. From the psychological perspective, the CKD may be considered as a state of chronic stress that may adversely affect the quality of life across all domains [2]. As a result of chronic stress, a higher prevalence of anxiety and depression that has been reported in these patients should not be surprising $[3,4]$. Stress, anxiety and depression are well known factors leading to insomnia - a common sleep problem - reported in CKD patients. So, quality of sleep frequently remnants insuficcient in subjects undergoing $\mathrm{HD}$. The CKD population is also susceptible to to preent OSA as these individuals are habitually in a state of extra fluid that can cause to upper airway narrowing by provoking edema. OSA is characterized by snoring, pauses in breath lasting at least $10 \mathrm{~s}$ and oxygen desaturation happening during sleep. Polysomnography is indispensable for its diagnosis [5]. Previous studies have reported that nearly a third of the CKD patients have comorbid OSA [6]. Beecroft and colleagues recommended that a narrow upper airway could be responsible for the OSA in these patients [7]. This narrowing is thought to be triggered by fluid excess and consequent upper airway edema as already cited.

OSA may be an individual such not recognized risk feature for sudden cardiac death (SCD) [8]. A rising group of evidence confirms strong associations between OSA and cardiovascular illnesses, including coronary artery disease, left ventricular dysfunction, hypertension, and arrhythmias [9]. OSA also is associated with increased mortality $[10,11]$. A particular relationship to SCD was suggested by the discovery that SCD is more likely to happen during usual sleep hours in patients with OSA, which is the period when SCD is slightest likely in individuals without OSA and in the general population [12]. While these data revealed that subjects with OSA know-how an altered daynight pattern of SCD, whether OSA growths the overall risk of SCD is not known. SCD balance sheet for 450,000 deaths annually in the United States [13]. The methodology to SCD risk stratification is hard, as modern treatments after myocardial infarction have altered

Correspondence to: Márcio Galindo Kiuchi, Rua Cel. Moreira César, 138 Centro, São Gonçalo, Rio de Janeiro, Brazil 24440-400; Tel:+55 (21) 26047744; Fax:+55 (21) 26047744; E-mail: marciokiuchi@gmail.com

Key words: obstructive sleep apnea. Non-sustained ventricular tachycardia, chronic kidney disease, left ventricular dysfunction, sudden cardiac death

Received: April 03, 2017; Accepted: May 02, 2017; Published: May 05, 2017 
the prognostic influence of many risk factors, and also because the massive majority of SCD occurs in persons without documented heart disease [14]. Current population studies propose that the risk of SCD is largely unrelated to $c$ ustomary risk factors and may include yet unrecognized parameters that directly disturb cardiac function and arrhythmogenesis $[15,16]$.

\section{Methods}

We conjectured that OSA is associated with an increased risk of ventricular arrhythmias freely of other risk issues and that the harshness of OSA is directly allied with the extent of this risk. In this curent study, we assessed the effects of clonazepam and zolpidem in OSA in patients with advanced CKD and mild left ventricular (LV) dysfunction.

This transversal study involved 30 patients with CKD stage 4, fifteen of them using clonazepam $2 \mathrm{mg}$ and the other 15 patients using zolpidem $10 \mathrm{mg}$ before to sleep due to a disturbance to sleep. This study was conducted at the Hospital e Clínica São Gonçalo, Rio de Janeiro, Brazil. Patients were recruited from July 2014 till July 2016 from the Arrhythmias and Artificial Cardiac Pacing Service of the same hospital. Enrolled patients met the following criteria: (i) a heart with an ejection fraction of $<50 \%$ as measured by cardiac magnetic resonance image (Simpson's method), (ii) use of clonazepam $2 \mathrm{mg}$ or zolpidem $10 \mathrm{mg}$ before sleeping due a insomnia, (iii) aged 18 to 85 years, (iv) patients with CKD stage 4: estimated glomerular filtration rate (eGFR) between 15 and $29 \mathrm{~mL} / \mathrm{min} / 1.73 \mathrm{~m}^{2}$, and no CKD patients: eGFR $>60 \mathrm{~mL} / \mathrm{min} / 1.73 \mathrm{~m} 2$ calculated using the Chronic Kidney Disease Epidemiology Collaboration (CKD-EPI) equation, and (v) the capacity to read, comprehend and sign the informed consent form, and attend the study [17]. Patients with any of the following were excluded: (i) pregnancy; (ii) valvular disease with significant adverse sequelae; (iii) unstable angina, myocardial infarction, transient ischemic attack or stroke previously; (iv) psychiatric disease; (v) the inability to be monitored clinically after the procedure; and (vi) a known addiction to alcohol or drugs that affects the intellect. The subjects were divided into two groups according to clonazepam or zolpidem use, and the polimsonography and 24-hour Holter monitoring were performed. The subjects were also submitted to 24-hour ABPM and cardiac magnetic resonance image.

\section{Statistical analysis}

The results are expressed as a mean and standard deviation for normally distributed data and as median with interquartile range otherwise. Comparisons between two-paired values were performed with the paired t-test in cases of a Gaussian distribution and by the Wilcoxon test otherwise. For normality of distribution, D'AgostinoPearson test was used. Comparisons between more than two-paired values were made by repeated-measures analysis of variance or by Kruskal-Wallis analysis of variance as appropriate, complemented by the post-hoc Tukey test. Categorical variables were compared with Fisher's exact test. A two-tailed P-value $<0.05$ was used as a criterion for statistical significance. All statistical analyses were performed using the program Graphpad Prism v 7.0 (Graphpad Software, La Jolla, CA, USA).

\section{Results}

The general features of the patients with CKD stage 4 in use of clonazepam or zolpidem are listed in Table 1. During the polysomnography, the group using clonazepam $2 \mathrm{mg}$ showed a higher apnea/hypopnea index events $(47.3 \pm 6.5$ events/hour) in comparison with the group using zolpidem $10 \mathrm{mg}(10.4 \pm 3.3$ events/hour),
$\mathrm{P}<0.0001$ (Figure 1). The 24-hour Holter monitoring presented a mean number of non-sustained ventricular tachycardia (NSVT) during the day, night, and whole period, respectively of $3.1 \pm 1.9,18.2 \pm 2.1$, and $10.7 \pm 2.0$ for the subjects using $2 \mathrm{mg}$ of clonazepam, as well as, $9.4 \pm$ $2.5,3.3 \pm 1.5$, and $6.3 \pm 1.8$ for the individuals using zolpidem $10 \mathrm{mg}$ (all the comparisons between groups into the same period were significant, $\mathrm{P}<0.0001$ for all of them), as shown in Figures $2 \mathrm{~A}, \mathrm{~B}$, and C. The inability to perform cardiac gadolinium-enhanced magnetic resonance image in patients with CKD stage 4 , due to the nephrotoxicity of a component of this substance is an important limitation because it could confirm exactly the zones of scar.

\section{Discussion}

OSA events cause systemic hypoxemia, which is sometimes severe and extended. These continuous oxygen desaturations in OSA patients may cause premature ventricular contraction. Hypoxemia allied to hypercapnia also activates the chemoreflex, which upsurges vascular sympathetic nerve traffic and serum catecholamines. Tachycardia and outbreaks in blood pressure at the end of apneas in amplified myocardial oxygen request at a time when oxygen saturation is at its deepest, a condition that may lead to myocardial ischemia and potentially dysrhythmic penalties. Subjects with OSA also have a paradoxical rise in coagulability through the night. Platelet activation and aggregation are augmented, fibrinogen levels are increased, and fibrinolytic activity is reduced throughout sleep in patients with OSA $[18,19]$. An enlarged danger of SCD in patients with OSA may also be clarified by heart autonomic dysfunction. The OSA affects mechanisms facilitating heart rate variability, comprising central nervous system combination between cardiac and ventilatory parasympathetic participations, the arterial baroreflex, and feedback from pulmonary stretch receptors [20]. As a result, heart rate variability is decreased in patients with OSA [21]. Moreover, the electrocardiographic QTc interval, which characterizes the duration of ventricular repolarization, and QTc interval dispersion, which reproduces the heterogeneity of repolarization, are atypical in patients with OSA. QTc interval dispersion correlates directly with the AHI and the length of nocturnal hypoxemia [22]. Additionally, the growth in sympathetic drive persists during the awake daytime period in subjects with OSA [23]. Whereas the exact link between autonomic function and SCD remain mostly unidentified, chronic sympathetic

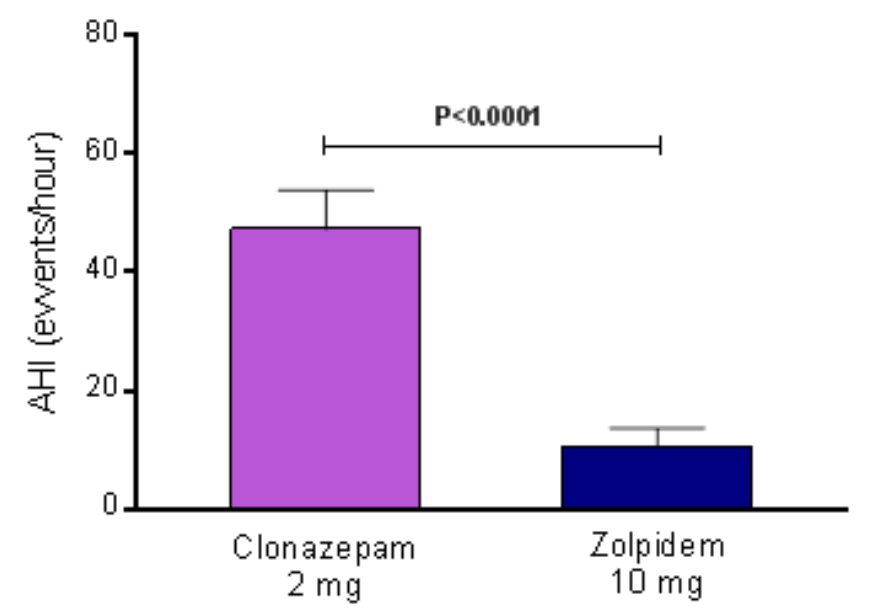

Figure 1. Apnea/hypopnea index (events/hour) during the polysomnography in the group using clonazepam $2 \mathrm{mg}$ in comparison with the group using zolpidem $10 \mathrm{mg}$. AHI, apnea/ hypopnea index; $\mathrm{N}=15$ for each group. 
(A)

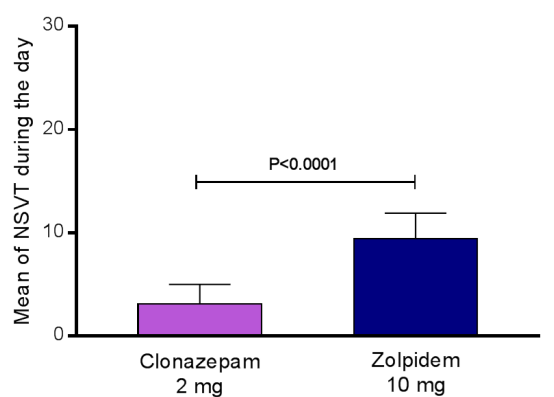

(B)

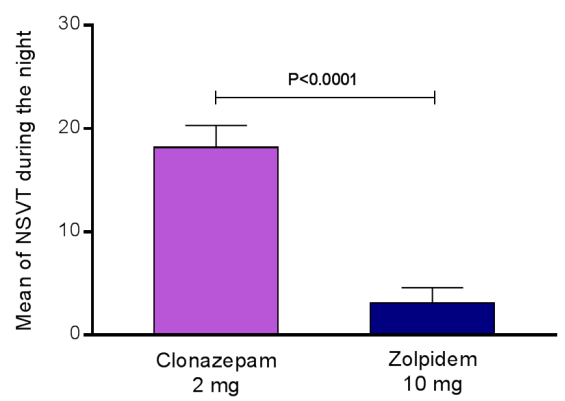

(C)

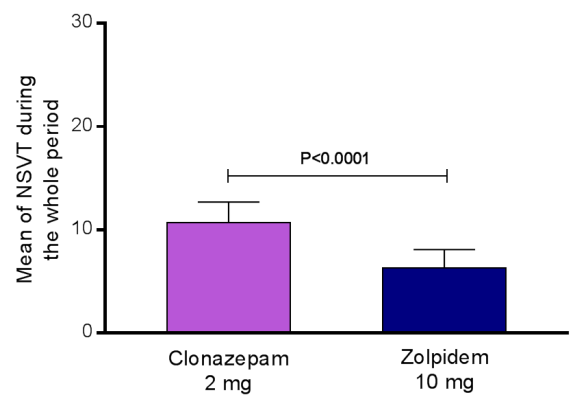

Figure 2. The mean number of non-sustained ventricular tachycardia recorded by the 24-hour Holter monitoring during the day (A), night (B), and whole period (C), for the subjects using $2 \mathrm{mg}$ of clonazepam, as well for the individuals using zolpidem $10 \mathrm{mg}$. NSVT, non-sustained ventricular tachycardia; $\mathrm{N}=15$ for each group.

Table 1. General features of patients with CKD stage 4 at baseline.

\begin{tabular}{|c|c|c|c|}
\hline Parameters & Clonazepam 2mg & Zolpidem 10mg & $\begin{array}{l}\text { Overall } \\
\text { P value }\end{array}$ \\
\hline $\mathrm{N}$ & 15 & 15 & --- \\
\hline Age, years & $60.2 \pm 11.3$ & $63.2 \pm 14.6$ & 0.5342 \\
\hline Body mass index, $\mathrm{kg} / \mathrm{m}^{2}$ & $28.1 \pm 5.0$ & $27.3 \pm 4.2$ & 0.6388 \\
\hline Male sex (\%) & $15(100 \%)$ & $13(87 \%)$ & 0.4828 \\
\hline White ethnicity (\%) & $10(67 \%)$ & $12(80 \%)$ & 0.6817 \\
\hline Hypertension & $15(100 \%)$ & $15(100 \%)$ & 1.0000 \\
\hline Type 2 Diabetes Mellitus & $8(53 \%)$ & $9(60 \%)$ & $>0.9999$ \\
\hline Creatinine, $\mathrm{mg} / \mathrm{dL}$ & $2.73 \pm 0.17$ & $2.80 \pm 0.12$ & 0.2032 \\
\hline $\mathrm{eGFR}, \mathrm{mL} / \mathrm{min} / 1.73 \mathrm{~m}^{2}$ & $26.0 \pm 2.7$ & $24.7 \pm 2.5$ & 0.1821 \\
\hline Albumin:creatinine ratio, $\mathrm{mg} / \mathrm{g}$ & $65.4 \pm 10.0$ & $72.2 \pm 12.3$ & 0.1078 \\
\hline \multicolumn{4}{|l|}{ Pharmacological treatment } \\
\hline ACE-inhibitors/ARB & $15(100 \%)$ & $15(100 \%)$ & 1.0000 \\
\hline Diuretics & $15(100 \%)$ & $15(100 \%)$ & 1.0000 \\
\hline Spironolactone & $15(100 \%)$ & $15(100 \%)$ & 1.0000 \\
\hline$\beta$-blockers & $15(100 \%)$ & $15(100 \%)$ & 1.0000 \\
\hline DHP Ca ${ }^{++}$channel blockers & $15(100 \%)$ & $15(100 \%)$ & 1.0000 \\
\hline Mean 24-hour Systolic/Diastolic ABPM, mmHg & $120.1 \pm 7.4 / 73.0 \pm 4.8$ & $119.2 \pm 8.8 / 70.5 \pm 6.0$ & $0.7640 / 0.2180$ \\
\hline \multicolumn{4}{|l|}{ Cardiac MRI parameters } \\
\hline Indexed LV mass/BSA, $\mathrm{g} / \mathrm{m}^{2}$ & $201.0 \pm 13.7$ & $194.6 \pm 20.1$ & 0.3169 \\
\hline LVEF, \% (Simpson) & $46.5 \pm 6.0$ & $45.7 \pm 5.4$ & 0.7040 \\
\hline LVEDVI, $\mathrm{mL} / \mathrm{m}^{2}$ & $109.8 \pm 5.4$ & $112.5 \pm 3.6$ & 0.1183 \\
\hline LVESVI, $\mathrm{mL} / \mathrm{m}^{2}$ & $45.7 \pm 2.0$ & $47.3 \pm 3.5$ & 0.1355 \\
\hline
\end{tabular}

Values are expressed as mean $\pm \mathrm{SD}$

ABPM: ambulatory blood pressure measurements;ACE: angiotensin-converting enzyme; ARB: angiotensin receptor blocker; CKD: chronic kidney disease; DHP: dihydropyridine; eGFR: estimated glomerular filtration rate; LV: left ventricular; LVEDVI: left ventricular end-diastolic volume index; LVESVI: left ventricular end-systolic volume index; MRI: magnetic resonance images; N: number of patients.

overdrive has been identified as a risk marker for SCD [24,25]. Also, OSA is existent in a large proportion of patients with heart failure and has been associated to chronic left ventricular dysfunction, therefore contributing to neurohumoral activation and myocardial remodeling that create the substrate for the SCD event $[26,27]$.

The mechanism of SCD is frequently well thought-out to be a ventricular arrhythmia. However, a number of other processes can simulator the unexpected and rapidly fatal presentation required by the definition of SCD. This may also result from other cardiovascular events, such as massive pulmonary embolism, subarachnoid hemorrhage, and aortic dissection. A different minus knew, but the theoretically important root of sudden death in individuals with OSA is the apnea by itself. An obstructive apnea event may not lay off due to unsuccessful stimulation mechanisms related to decreased chemosensitivity, which leads to deep cerebral hypoxemia and death. Three such cases, with polysomnographic and electrocardiographic monitoring, have been reported previously $[28,29]$.

\section{Conclusion}

So, we can conclude that there were a highest number of AHI events in patients using clonazepam $2 \mathrm{mg}$ than in those using zolpidem 10 $\mathrm{mg}$, as well as, a major incidence of NSVT in the first group compared to the second one, during the whole period recorded by the 24-hour Holter monitoring, leading us to believe that zolpidem is a safer drug for patients with CKD at more advanced stages.

\section{Conflict of interest}

All authors certify that they have no affiliations with or involvement in any organization or entity with any financial interest (such as honoraria; educational grants; participation in speakers' bureaus; 
membership, employment, consultancies, stock ownership, or other equity interest; and expert testimony or patent-licensing arrangements), or non-financial interest (such as personal or professional relationships, affiliations, knowledge or beliefs) in the subject matter or materials discussed in this manuscript.

\section{Funding}

Pacemed provided financial support in the form of US $\$ 100,000$ funding. The sponsor had no role in the design or conduct of this research.

\section{Ethical approval}

All procedures performed in studies involving human participants were in accordance with the ethical standards of the institutional and/ or national research committee and with the 1964 Helsinki declaration and its later amendments or comparable ethical standards.

\section{Informed consent}

Informed consent was obtained from all individual participants included in the study.

\section{Acknowledgements}

We would like to thank Pacemed and all the participants.

\section{References}

1. Noda A, Nakai S, Soga T, Sugiura T, Iwayama N, et al. (2006) Factors contributing to sleep disturbance and hypnotic drug use in hemodialysis patients. Intern Med 45: 1273-1278. [Crossref]

2. Parker KP, Bliwise DL, Bailey JL, Rye DB (2005) Polysomnographic measures of nocturnal sleep in patients on chronic, intermittent daytime haemodialysis vs. those with chronic kidney disease. Nephrol Dial Transplant 20: 1422-1428. [Crossref]

3. Montinaro V, Iaffaldano GP, Granata S, Porcelli P, Todarello O, et al. (2010) Emotional symptoms, quality of life and cytokine profile in hemodialysis patients. Clin Nephrol 73: 36-43. [Crossref]

4. Peng T, Hu Z, Guo L, Xia Q, Li D, et al. (2012) Relationship between psychiatric disorders and quality of life in nondialysis patients with chronic kidney disease. $\mathrm{Am} \mathrm{J}$ Med Sci 345: 218-221. [Crossref]

5. American academy of sleep medicine (2005) International Classification of Sleep Disorders: Diagnostic and Coding Manual, (ICSD- 2). $2^{\text {nd }}$ ed. Westchester: American Sleep Disorders Association.

6. Tada T, Kusano KF, Ogawa A, Iwasaki J, Sakuragi S, et al. (2007) The predictors of central and obstructive sleep apnoea in haemodialysis patients. Nephrol Dial Transplant 22: 1190-1197. [Crossref]

7. Beecroft JM, Pierratos A, Hanly PJ (2009) Clinical presentation of obstructive sleep apnea in patients with end-stage renal disease. J Clin Sleep Med 5: 115-121. [Crossref]

8. Gami AS, Somers VK (2007) Sudden death and obstructive sleep apnea. In: Electrical Diseases of the Heart: Genetics, Mechanisms, Treatment, Prevention. London: Springer.

9. Gami AS, Somers VK (2007) Sleep apnea and cardiovascular disease. In: Braunwald's Heart Disease: A Textbook of Cardiovascular Medicine. 8. Philadelphia: Saunders.

10. Marshall NS, Wong KK, Liu PY, Cullen SR, Knuiman MW, et al. (2008) Sleep apnea as an independent risk factor for all-cause mortality: the Busselton Health Study. Sleep 31: 1079-1085. [Crossref]
11. Young T, Finn L, Peppard PE, Szklo-Coxe M, Austin D, et al. (2008) Sleep disordered breathing and mortality: eighteen-year follow-up of the Wisconsin sleep cohort. Sleep. 31: 1071-1078. [Crossref]

12. Gami AS, Howard DE, Olson EJ, Somers VK (2005) Day-night pattern of sudden death in obstructive sleep apnea. $N$ Engl J Med 352: 1206-1214. [Crossref]

13. Anonymous. Preventing heart disease and stroke: addressing the nation's leading killers. Atlanta: Centers for Disease Control and Prevention, Department of Health And Human Services; 2003.

14. Myerburg RJ, Kessler KM, Castellanos A (1992) Sudden cardiac death. Structure, function, and time-dependence of risk. Circulation 85: I2-10. [Crossref]

15. Spooner PM, Albert C, Benjamin EJ, Boineau R, Elston RC, et al. (2001) Sudden cardiac death, genes, and arrhythmogenesis: consideration of new population and mechanistic approaches from a national heart, lung, and blood institute workshop, part I. Circulation 103: 2361-2364. [Crossref]

16. Spooner PM, Albert C, Benjamin EJ, Boineau R, Elston RC, et al. (2001) Sudden cardiac death, genes, and arrhythmogenesis: consideration of new population and mechanistic approaches from a National Heart, Lung, and Blood Institute workshop, Part II. Circulation 103: 2447-2452. [Crossref]

17. Levey AS, Stevens LA, Schmid CH, Zhang YL, Castro AF III, et al. (2009) A new equation to estimate glomerular filtration rate. Ann Intern Med 150: 604-612. [Crossref]

18. Gami AS, Somers VK (2007) Sleep apnea and cardiovascular disease. In: Braunwald's Heart Disease: A Textbook of Cardiovascular Medicine 8. Philadelphia: Saunders.

19. Gami AS, Olson EJ, Shen WK, Wright RS, Ballman KV, et al. (2013) Obstructive sleep apnea and the risk of sudden cardiac death: a longitudinal study of 10,701 adults. $J \mathrm{Am}$ Coll Cardiol 62: 610-616. [Crossref]

20. Narkiewicz K, Pesek CA, Kato M, Phillips BG, Davison DE, et al. (1998) Baroreflex control of sympathetic nerve activity and heart rate in obstructive sleep apnea. Hypertension 32: 1039-1043. [Crossref]

21. Roche F, Xuong AN, Court-Fortune I, Costes F, Pichot V, et al. (2003) Relationship among the severity of sleep apnea syndrome, cardiac arrhythmias, and autonomic imbalance. Pacing Clin Electrophysiol. 26: 669-677. [Crossref]

22. Nakamura T, Chin K, Hosokawa R, Takahashi K, Sumi K, et al. (2004) Corrected QT dispersion and cardiac sympathetic function in patients with obstructive sleep apneahypopnea syndrome. Chest 125: 2107-2114. [Crossref]

23. Somers VK, Dyken ME, Clary MP, Abboud FM (1995) Sympathetic neural mechanisms in obstructive sleep apnea. J Clin Invest 96: 1897-1904. [Crossref]

24. Zipes DP1, Rubart M (2006) Neural modulation of cardiac arrhythmias and sudden cardiac death. Heart Rhythm 3: 108-113. [Crossref]

25. La Rovere MT, Pinna GD, Hohnloser SH, Marcus FI, Mortara A, et al. (2001) Baroreflex sensitivity and heart rate variability in the identification of patients at risk for life-threatening arrhythmias: implications for clinical trials. Circulation 103: 20722077. [Crossref]

26. Tkacova R, Rankin F, Fitzgerald FS, Floras JS, Bradley TD (1998) Effects of continuous positive airway pressure on obstructive sleep apnea and left ventricular afterload in patients with heart failure. Circulation 98: 2269-2275. [Crossref]

27. Kaneko Y, Floras JS, Usui K, Plante J, Tkacova R, et al. (2003) Cardiovascular effects of continuous positive airway pressure in patients with heart failure and obstructive sleep apnea. $N$ Engl J Med. 348: 1233-1241.

28. Dyken ME, Yamada T, Glenn CL, Berger HA (2004) Obstructive sleep apnea associated with cerebral hypoxemia and death. Neurology 62: 491-493. [Crossref]

29. Pearce S, Saunders P (2003) Obstructive sleep apnoea can directly cause death. Thorax 58: 369. [Crossref]

Copyright: (C2017 Kiuchi MG. This is an open-access article distributed under the terms of the Creative Commons Attribution License, which permits unrestricted use, distribution, and reproduction in any medium, provided the original author and source are credited. 